\title{
Analysis of the El Niño/La Niña-Southern Oscillation variability and malaria in the Estado Sucre, Venezuela
}

\author{
Laura Delgado-Petrocelli ${ }^{1}$, Karenia Córdova², Alberto Camardiel ${ }^{3}$, Víctor H. Aguilar ${ }^{4}$, Denise \\ Hernández ${ }^{4}$, Santiago Ramos ${ }^{1}$ \\ ${ }^{1}$ Ecological Information Systems and Environmental Modeling Laboratory, Institute of Tropical Zoology, \\ Central University of Caracas, Caracas, Venezuela; ${ }^{2}$ Institute of Geography and Regional Development, Faculty \\ of Humanities and Education, Environmental and Energy Area, Central University of Caracas, Caracas, \\ Venezuela; ${ }^{3}$ Postgraduate Area in Statistics and Actuarial Sciences, Faculty of Economy and Social Sciences, \\ Central University of Caracas, Caracas, Venezuela; ${ }^{4}$ Institute of Geography and Regional Development, Faculty \\ of Humanities and Education, Central University of Caracas, Caracas, Venezuela
}

\begin{abstract}
The last decade has seen an unprecedented, worldwide acceleration of environmental and climate changes. These processes impact the dynamics of natural systems, which include components associated with human communities such as vector-borne diseases. The dynamics of environmental and climate variables, altered by global change as reported by the Intergovernmental Panel on Climate Change, affect the distribution of many tropical diseases. Complex systems, e.g. the El Niño/La Niña-Southern Oscillation (ENSO), in which environmental variables operate synergistically, can provoke the reemergence and emergence of vector-borne diseases at new sites. This research investigated the influence of ENSO events on malaria incidence by determining the relationship between climate variations, expressed as warm, cold and neutral phases, and their relation to the number of malaria cases in some north-eastern municipalities of Venezuela (Estado Sucre) during the period 1990-2000. Significant differences in malaria incidence were found, particularly in the La Niña ENSO phases (cold) of moderate intensity. These findings should be taken into account for surveillance and control in the future as they shed light on important indicators that can lead to reduced vulnerability to malaria.
\end{abstract}

Keywords: climate variability, El Niño / La Niña-Southern Oscillation, geographical information systems, malaria, Venezuela.

\section{Introduction}

Recent epidemiological and public health management research has generated information related to the consequences of climate change that are of great concern for human health. Poveda et al. (2000) investigated the incidence of malaria and dengue in Colombia caused by the El Niño/La Niña-Southern Oscillation (ENSO), the fluctuating climate pattern with a period around five years occurring in the tropical Pacific Ocean. They found a correlation between El Niño (the ENSO warm phase) expressed as a shortening of the lifecycles of the two vectors and a corresponding extension during La Niña (the ENSO cold phase) resulting in fewer cases of malaria and dengue in the latter case. Re-emergence of these diseases in Venezuela may also be related to ENSO

Corresponding author:

Laura Delgado-Petrocelli

Ecological Information Systems and Environmental Modeling

Laboratory, Institute of Tropical Zoology,

Central University of Caracas, Venezuela

Tel. +58 212605 1311; Fax +58 2126051204

E-mail: laura.delgado@ciens.ucv.ve events, including the elevated malaria incidence in some areas such as the Estado Sucre in northeast Venezuela as discussed previously by Delgado et al. (2004a). Estado Sucre constitutes one of the country's three malaria foci, and there is a high risk for malaria transmission in this region of the country. The area has a low human development index (HDI), predominance of low-technology agriculture and harvest and is geographically characterized by extensive and varied wetland systems, factors which favour malaria endemicity (Delgado, 2005; Delgado et al., 2004b, 2006, 2007, 2009).

The malaria risk can be studied by eco-epidemiological research guided by satellite-generated remote sensing and geographical information systems (GIS). Data, derived from the study of malaria epidemiology and climate, provide insight into the effects on the dynamics of this disease and could help improve the design of health programmes, surveillance and control strategies. Landscape ecology concepts make use of this information and have revealed three new ways to approach climate change and health (DelgadoPetrocelli and Ramos, 2009). Two of these are based on ecological features, while the third is related to 
human activities. This has lead to cooperation with the health authorities in the study of public health problems related to poverty, low rural development and uncontrolled land transformation. With respect to the former two, it is possible to control the impact of vector-borne infectious diseases through surveillance and control systems primarily directed at transmission, i.e. interference with vector lifecycles. Thus, this approach requires an understanding of the overall ecological system and implies high-resolution, epidemiological studies at the local level, which consider functional features that define landscape-related patterns and spatio-temporal structures.

The third approach relates to the human role in nature with a focus on the landscape and the increasing fragmentation caused by exploitation of land resources. This includes an emerging, ecological feature derived from the concept of connectedness (Muscat and Buhagiar, 2006), a concept derived from mathematical topology theory but with simple practical application: two separate areas (nodes) within a larger landscape can only communicate if there exists at least one path connecting them. For example, a mosquito metapopulation (Levins, 1969, 1970; Fahrig and Paloheimo, 1988; Cronin, 2003) located in node "Y", its members can only move to another location (say node "X") if there is a continuous geographical connection (which can be straightforward or restricted in various ways). If such a connection is found, the "Y" metapopulation may relocate to node " $\mathrm{X}$ ". If there are another similar metapopulation in " $\mathrm{X}$ ", the same chance exists for both and they may interact using the path. In ecological terms, this means that the number of reliable paths, existing in a particular interval of time, may be used by metapopulations to interact. The total effect of different populations at each node may merge into one population (depending how easy the existing paths are to navigate) that dominates the whole landscape. However, depending upon condition imposed by the climate or other general physical-natural fluctuations, paths can disappear or became more difficult to navigate. In the particular case of the Paria peninsula, man-made alterations of the landscape have favoured connectedness among relative close nodes; in other words, facilitated the connectivity among the main mosquito habitats. This concept concerns the probability that nodes, defined as landscape patches on a continuous line in a digital map, are topologically linked to all lines that meet there. The processes associated with such nodes and lines may form network interactions that depend on if they are permanently or intermittently connected. In terms of time, it may pres- ent a frequency dynamic defined by the number of times that any two nodes interact. Spatially it may lead to a different dynamic if a wide or narrow network of interconnected nodes is configured in a region, i.e. the number of nodes concurrently interacting within a particular period of time.

Landscape ecological theory considers nodes as patches within the spatial arrangement of a matrix segmented into patches and corridors (Fahrig and Merriam 1985; Gustafson and Gardner, 1996; Turner et al., 2001). These properties only emerge under a high-resolution, spatial analysis, which is not always possible. In this paper, however, we offer evidence for local consequences of events of global significance, which corresponds to a broad, coarse-grain approach aimed at elucidating how change in a local system pattern can be derived from a variable, global climatic event. The objective was to determine the relationship between global climate variability, expressed as warm, cold and neutral phases, and the occurrence of malaria.

\section{Materials and methods}

\section{Study area}

Estado Sucre, one of Venezuela's 23 states, covers an area of $11,800 \mathrm{~km}^{2}$ in the north-eastern coastal region of the country (Fig. 1). It is located between longitude $61^{\circ} 50^{\prime} 44^{\prime \prime} \mathrm{W}$ and $64^{\circ} 30^{\prime} 00^{\prime \prime} \mathrm{W}$, and latitude $10^{\circ} 13^{\prime} 10^{\prime \prime} \mathrm{N}$ and $10^{\circ} 44^{\prime} 10^{\prime \prime} \mathrm{N}$ and is divided into 15 municipalities.

\section{Geospatial data}

Estado Sucre encompasses most of Venezuela's north-eastern malaria focus. The MapInfo application, version 7.5 (http://www.pbinsight.com/welcome/mapinfo) generated a set of basic cover-layers at the regional scale of 1:100,000. The database used included malaria cases reported for the period 19902000 and was indexed with respect to the three Southern Oscillation Index (SOI) climate variables (warm, neutral or cold). The data were explored with the statistical software Minitab, version 14 (http://www.minitab.com/en-US/default.aspx) and analysed with geospatial techniques generating thematic maps to explain the correlation between malaria cases and the ENSO variable. This was done to investigate whether or not a statistical significant dependence effect could be found between the number of malaria cases and ENSO intensity by time and space (decade and municipality). 




Fig.1. The study area showing the Venezuelan state of Sucre (Estado Sucre) divided into four sanitary demarcations by the local health authorities.

Thematic maps were generated from the 1:100,000 scale, official base-map with MapInfo software. All the thematic layers were Universal Transverse Mercator (UTM) zone 20, geo-coded from the local reference La Canoa Datum (the Geoid Model based on PSAD56 parameters and calculated for the Venezuela territory using La Canoa locality coordinates us primary references). The geopolitical administrative layer, consisting of 15 polygons adjusted for municipality boundaries (defined as the municipal resolution) was complemented with an attributed data model that was developed not only taking into account the various ENSO phases but also their intensities (weak, moderate or strong). This was done according to SOI values and malaria cases by municipality for each phase and strength. Three intensity intervals were determined according to the SOI pressure value anomalies: weak (0.5-0.99), moderate (1.0-2.99) and strong (3.0-4.99). SOI values correspond to region Niño 3+4, for the 1990-2000 period (area of occurrence of the
ENSO event in the equatorial pacific $2+1,3$ and $3+4$ ) (Fig. 2) taken from the published records of the National Oceanic and Atmospheric Administration (NOAA) Earth System Research Laboratory (http://www.noaa.gov). El Niño phase (warm) SOI values carry a negative sign (-) indicating low pressure, while the opposite $(+)$ indicates the cold phase and high pressure (La Niña).

\section{Epidemiological data}

The local health authorities have subdivided Estado Sucre into four administrative sanitary demarcations designated A, B, C and D to assist the work with populations at risk (Fig. 1). Data gathered for the period 1990-2000 of monthly and yearly reported malaria cases by town and municipality were obtained from records at the regional office of Environmental Sanitation and Sanitary Control of Malaria, Zone 11, at Carupano, Estado Sucre, Venezuela.



Fig. 2. The geographical distribution of the ENSO regions. 


\section{Results}

The ENSO phenomena was found to impact Estado Sucre in diverse ways and strengths, creating a differential expression of vector-borne diseases in coastal areas and some inland regions according to phase and year. The statistical analysis indicates that moderate ENSO phenomena (warm and cold phases) has a significant effect on malaria. The malaria incidence varied by municipality, ENSO event and year. The Cajigal municipality showed the highest incidence, regardless of ENSO phase or year. The Sucre municipality showed a high malaria incidence that varied with ENSO events and year. Both these municipalities are situated at low terrain slopes and elevations. Rudimentary agricultural activities, and land use changes supporting these activities, are common in both municipalities including the presence of excess wetlands and a high proportion of rural population.

The ENSO phase- and intensity-grouped SOI values, combined with municipality-grouped malaria cases, were represented as thematic layers to show the spatial distribution of the disease for the period 1990-2000 including a layer depicting the neutral ENSO phase (Figs. 3-5). These maps provide a synthesis of spatiotemporal incidence of malaria in the Sucre municipalities during the various ENSO phases revealing a greater number of malaria cases during the cold phases for all municipalities. For example, there was a significant correlation between high incidence of malaria
(IM) by municipality and moderate El Niño and moderate La Niña events, and also with low malaria incidence and weak La Niña events.

During the decade ending in 2000, the highest number of cases $(4,800)$ appeared during La Niña phase (cold) in 1999. In the El Niño phase (warm) there were 3,700 cases, while there were only 2,000 cases during the neutral phases such as those in 1990. Figs. 3a, 3b and $3 \mathrm{c}$ are thematic maps showing SOI climatic variability during the warm phase and cases of malaria by municipality in Estado Sucre during the previous decade. Sanitary demarcations D (Sucre municipality) and A (Cajigal municipality) presented the highest malaria incidence during warm, moderate ENSO events, while fewer cases (down to $10-33 \%$ cases) were observed during either weak or strong ENSO events (Figs. 3a and 3c). Similarly, the same behaviour was observed during cold, moderate ENSO events (La Niña) in the municipalities of Sucre, Cajigal, and also Benitez (B sanitary demarcation), but the number of cases dropped when cold ENSO events were either weak or strong (down by $3 \%$ and $14 \%$ of cases, respectively). In Figs. $4 \mathrm{a}, 4 \mathrm{~b}$ and $4 \mathrm{c}$, the thematic maps show climate variability and malaria cases.

Fig. 5 shows malaria cases during the neutral phase. Some municipalities had a variable number of cases such as the Sucre municipality, while others showed a stable endemic regime of malaria with up to 2,000 cases, e.g. the Cajigal municipality, which exhibited independence from the ENSO events. (a)

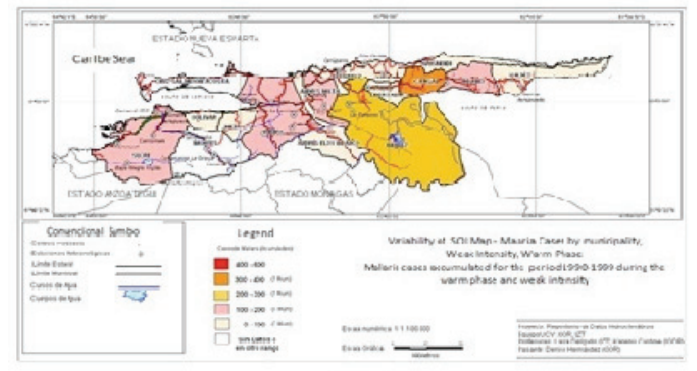



(b)

(c)



Fig. 3. (a) ENSO warm, weak phase and malaria cases by municipality in 1990-1999; (b) ENSO warm, moderate-strength phase and malaria cases by municipality 1990-1999; (c) ENSO warm, strong phase and malaria cases by municipality 1990-1999. 
(a)
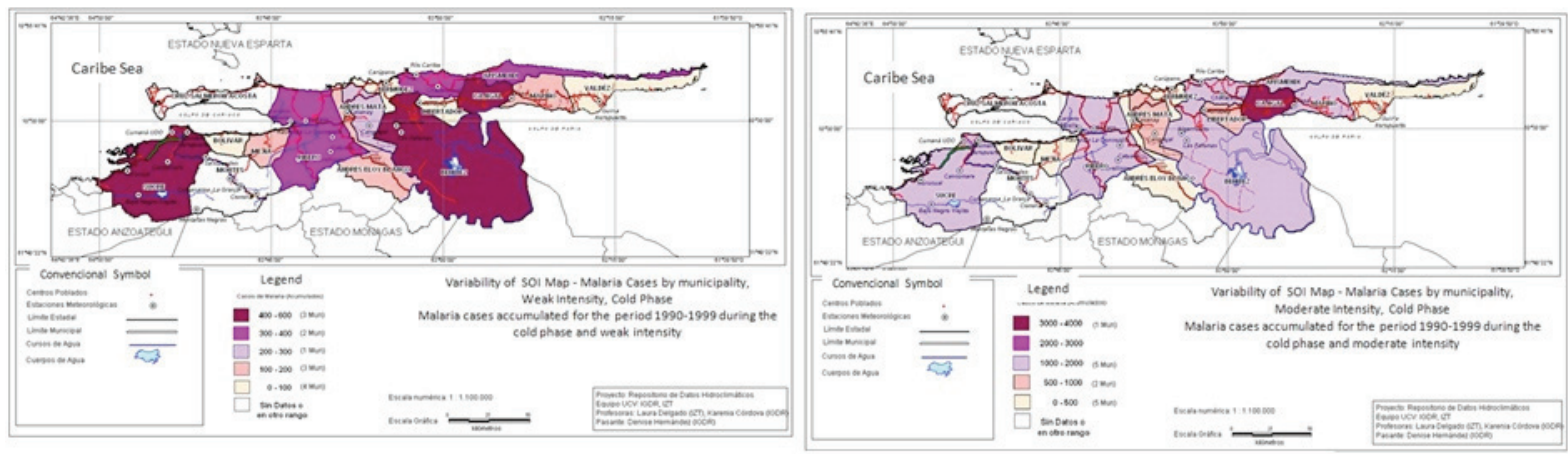

(b)

(c)



Fig. 4. (a) ENSO cold, weak phase and malaria cases by municipality in 1990-1999; (b) ENSO cold, moderate-strength phase and malaria cases by municipality in 1990-1999; (c) ENSO cold, strong phase and malaria cases by municipality in 1990-1999.

A one-way analysis of variance (ANOVA) was performed to find evidence that the true means of IM differ with ENSO intensity event when categorized in neutral phase and weak, moderate or strong intensity. The F statistic showed a significant outcome at a level smaller than $0.001 \%$, so we can be confident that true means really are different as suggested by Fig. 6: the true IM mean for moderate intensity $>$ true mean of the IM for neutral phase $>$ true mean of the IM for weak intensity $=$ the true mean of the IM for strong intensity.

\section{Discussion}

Evidence shown here is in agreement with results from previous malaria studies performed in Estado Sucre (Bouma and Dye, 1997; Barrera et al., 1998, 1999). These authors pointed out the possible relationship between climate variability and IM in the region. The present results reinforce this claim. However, the referenced studies did not account specifically for ENSO phase intensities and they were

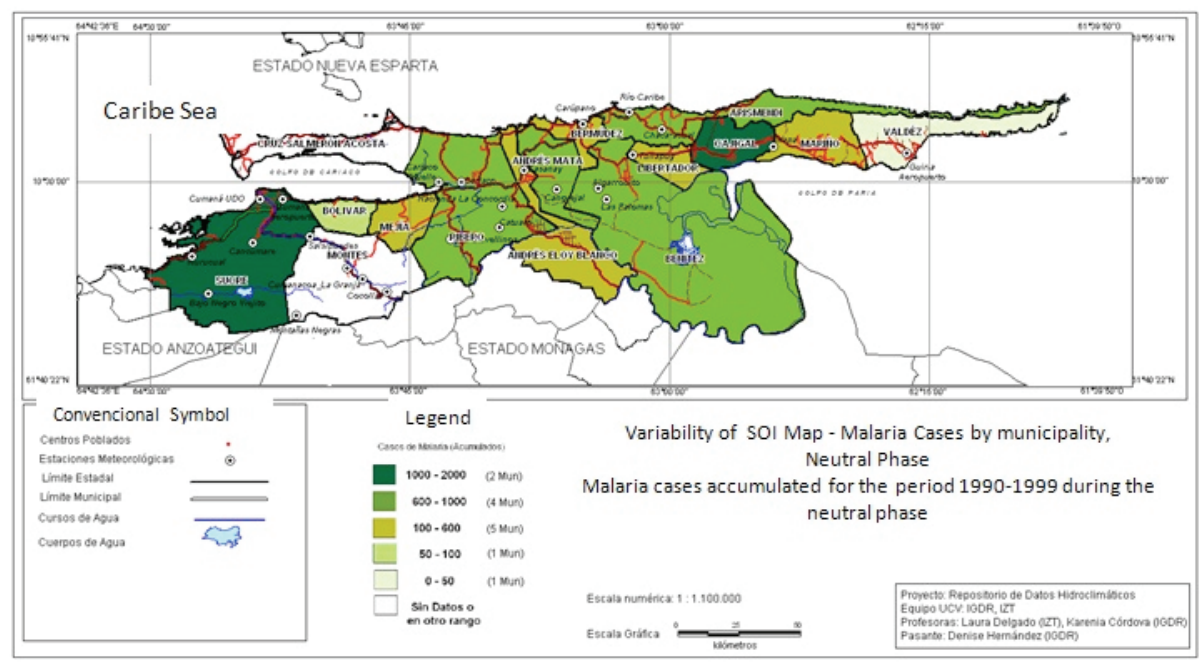

Fig. 5. ENSO neutral phase and malaria cases by municipality 1990-1999. 


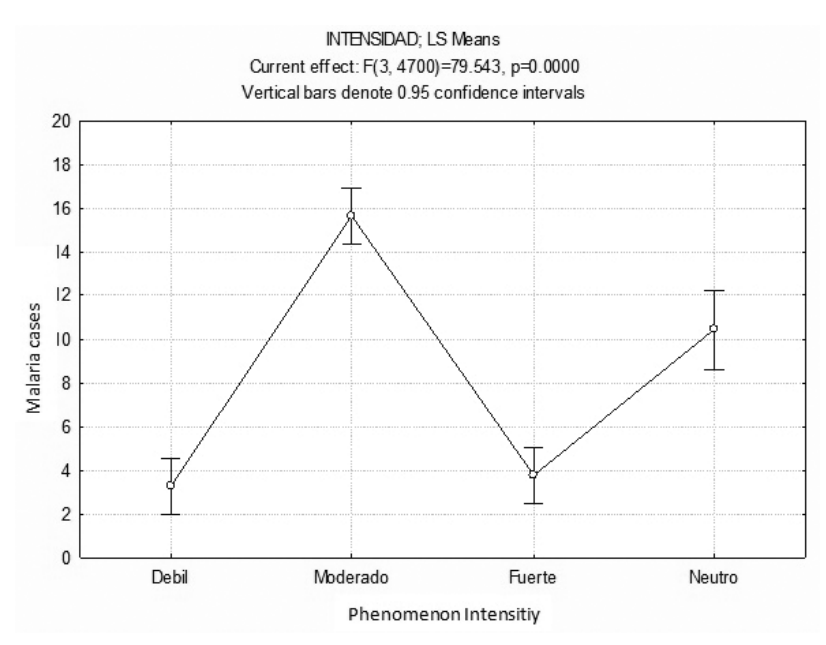

Fig. 6. ANOVA tests for ENSO strengths and malaria cases.

neutral in the sense of how global climatic events may act on the local expression of malaria. Our current research in Estado Sucre indicates that both moderate El Niño and moderate La Niña significantly influence the IM with respect to the ecological system translating into a significant variation in the number of malaria cases. Thus, although there might be a weak correlation between ENSO events and the IM, elements involved are insufficient to predispose the system to a significant effect on incidence. Other elements must also be taken into account to elucidate all the factors acting on the malaria dynamics in the region including public health policies applied during the study period or local ecology that may influence malaria prevalence in the region in relation to ENSO events.

In the context of landscape ecology theory, a matrix represents all the components and features that form the natural environment, which includes the climatic condition and its dynamic pattern in relation to disease, in this case malaria. This can be ecologically interpreted as a vector-related subsystem, which may lead to effects with regard to vector life cycles due to temperature/moisture combinations, delays or variation on precipitation periods altering the oviposition rate and metamorphic processes. Incremental variation in temperature may act on metabolic rates during the entire life cycle or it may vary the offspring sex ratio altering the gonotrophic cycle (Löwenberg-Neto and Navarro-Silva, 2004). Alternatively, local analysis, corresponding to fine-grain resolutions, may elucidate the impact of spatial features related to connectedness between patches that may explain the persistence of malaria in municipalities such as Cajigal and Benitez and nearby localities. In these places, the natural landscape conditions are such that the matrix fre- quency and extension of connectivity allows the vector subsystem to approach its optimal niche resulting in permanent malaria foci rather than intermittent ones. When this is realized it makes the subsystem prone to become persistent for the long term or at least sustainable when using the concept in the ecological context rather than its entropic interpretation. Indeed, recent malaria studies in the Paria peninsula support the concept of local hot and cold spots (Grillet et al., 2010) and the importance of the "epidemiological corridor" as a landscape pattern feature (Delgado-Petrocelli et al., 2011). Fig. 5 shows that ENSO events are related to fluctuations in the number of malaria cases, while the permanency of malaria associated with specific localities like Cajigal and Benitez. This supports the idea that ENSO events have limited influence in determining the magnitude and intensity of malaria in certain localities where optimum ecological niche conditions converge as they do in Estado Sucre.

\section{Conclusions}

The integrating and synthesising capabilities of geospatial tools depict more clearly the relationship between climate variability and local malaria dynamics. This allows improved support in the design and implementation of surveillance and control measures, especially climate-linked prevention measures, to reduce the vulnerability of local communities.

Compared to the warm and neutral ENSO events, a greater number of malaria cases were found during the cold phases. However, IM differences were also observed to depend on ENSO intensity as most cases occurred at moderate intensities corresponding to either cold or warm events. In addition, the particular geographical features in the Sucre, Cajigal and Benitez municipalities, such as the presence of wetlands and man-made alteration of the natural landscape by changing land use and agriculture together with the inadequate quality of life, associated with the latter two municipalities, directly favour mosquito population to colonize previously non-occupied patches during prolonged periods. This effect, relating spatial connectedness among landscape patches and improved conditions for mosquito survival, makes it possible for malaria to be considered locally endemic in these municipalities and ecologically appreciated as subsystem, independent of ENSO phase or intensity.

The system analysis approach allows a more complete explanation of the role of different ecological components. While the ENSO events impact the overall natural landscape matrix, local conditions allow 
vector subsystems to reach stability close to permanent sustainability. Here the interconnection of spatial relationships emerge as an important system feature, where disease-prone patches develop connectivity, establishing a set of permanent endemic interrelations and eventually producing a network of emerging endemic corridors. In this way, landscape and climate variables impose a rhythm of geographically variable cold and hot spots supported by the interrelation between vulnerable humans and regional mosquito populations.

\section{Acknowledgements}

Funding was provided by project $\mathrm{CDCH} \mathrm{N}^{\circ}$ 03-31-39812005, and projects FONACIT UCV-2001001850 and BIDFONACITII G-2005000184. Authors especially thank staff members of Zone 11 - Malariología (Fundasalud) Carúpano, and personnel from sanitary demarcations for their helpful cooperation, especially Ing. Luis Díaz and Dr. Darío González. Adelso "Chato" Malavé is thanked for field assistance. We thank our anonymous reviewers for their valuable corrections and recommendations.

\section{References}

Barrera R, Grillet ME, Rangel Y, Berti J, Ache A, 1998. Estudio eco-epidemiológico de la reintroducción de malaria en el nororiente de Venezuela mediante sistemas de información geográfica y sensores remotos. Bol Dir Malariol San Amb 38, 14-30.

Barrera R, Grillet ME, Rangel Y, Berti J, Ache A, 1999. Temporal and spatial patterns of malaria reinfection in northeastern Venezuela. Am J Trop Med Hyg 61, 784-790.

Bouma MJ, Dye C, 1997. Cycles of malaria associated with El Niño in Venezuela. JAMA-J Am Med Assoc 278, 1772-1774.

Cronin JT, 2003. Movement and spatial population structure of a prairie planthopper. Ecology 84, 1179-1188.

Delgado L, 2005. La dinámica espacio-temporal del sistema malaria en el foco nor-oriental de Venezuela. Acta Biol Venez 25, 57-66

Delgado L, Córdova K, Rodríguez AJ, 2004a. Epidemiological impact of climatic variation on malaria dynamics in a northeastern region of Venezuela. Int J Infect Dis 8, S23-S24.

Delgado L, Ramos S, Camardiel A, 2007. La malaria y su contexto espacial. El caso particular del State of Sucre en Venezuela. XI conferencia iberoamericana de sistemas de información geográfica (XI CONFIBSIG).

Delgado L, Ramos S, Camardiel A, Liberal L, 2009. Landscape ecology and geospatial tool applications in tropical medicine: malaria in Sucre state, Venezuela. Trop Med Int Health 14, 24. Delgado L, Ramos S, Martínez N, 2004b. Antropogénesis y persistencia de malaria, State of Sucre-Venezuela. XI simposio latinoamericano en percepción remota y sistemas de información espacial (SELPER).

Delgado L, Ramos S, Martínez N, Camardiel A, 2006. Tecnologías geospaciales y su utilidad en la reducción de la vulnerabilidad. Caso especial malaria. Sucre-Venezuela. XII simposio latinoamericano en percepción remota y sistemas de información espacial (SELPER).

Delgado-Petrocelli L, Camardiel A, Aguilar VH, Martínez N, Córdova K, Ramos S, 2011. Geospatial tools for the identification a malaria corridor in State of Sucre, a Venezuelan north-eastern State. Geospat Health 5, 169-176.

Delgado-Petrocelli L, Ramos S, 2009. Ecoepidemiología Panorámica: Nuevos Paradigmas para Enfrentar las Endemias Rurales en América Latina. En "Enfoques y Temáticas de Entomología. ISBN 978-980-12-3750-1”. Editado por el XXI Congreso Venezolano de Entomología. Capítulo 7, pp. 115-136. Fahrig L, Merrian G, 1985. Habitat patch connectivity and population survival. Ecology 66, 1762-1768.

Fahrig L, Paloheimo J, 1988. Effect of spatial arrangement of habitat patches on local population size. Ecology 69, 468-475. Grillet ME, Barrera R, Martínez JE, Berti J, Fortin MJ, 2010. Disentangling the effect of local and global effect on a mosquito-borne infection in a neotropical heterogeneous environment. Am J Trop Med Hyg 82, 194-201.

Gustafson EJ, Gadner RH, 1996. The effect of landscape heterogeneity on the probability of patch colonization. Ecology 77, 94-107.

Levins R, 1969. Some demographic and genetic consequences of environmental heterogeneity for biological control. Bulletin of the Entomological Society of America 15, 237-240.

Levins R, 1970. Extinctions. In Some Mathematical Questions in Biology: Lectures on Mathematics in the Life Sciences. American Mathematical Society, Providence, pp. 77-107.

Löwenberg-Neto P, Navarro-Silva MA, 2004. Development, longevity, gonotrophic cycle and oviposition of Aedes albopictus Skuse (Diptera: Culicidae) under cyclic temperatures. Neotropical. Entomology 331, 29-33.

Muscat J, Buhagiar D, 2006. Connective spaces. Men Fac Sci Eng, Shimane University, series B, Math Sci 39, 1-13.

Poveda G, Graham NE, Epstein PR, Rojas W, Quis ML, 2000. Climate and ENSO variability associated with vector-borne diseases in Colombia. In: El Niño and the southern oscillation, multiscale variability and global and regional impacts. First edition. Cambridge University Press. London, UK.

Turner M, Gardner R, O Neill R, 2001. Landscape ecology in theory and practice. Pattern and process. Springer-Verlag, New York. pp. 389. 